This is a post-peer-review, pre-copyedit version of an article published in 'International Journal of Mental Health and Addiction'. The final authenticated version is available online at: https://doi.org/10.1007/s11469-018-9978-5.

\title{
Problematic Gaming and Subjective Well-Being: How Does Mindfulness Play a Role?
}

\begin{abstract}
Video game use becomes problematic when it disrupts the ability to fulfill social and personal responsibilities. It has also been associated with poorer subjective well-being (i.e., life satisfaction, positive and negative affectivity). Research suggests that dispositional (or trait) mindfulness (e.g., general tendency to have focused awareness of the present moment, with acceptance) is associated with greater subjective well-being. Building on research on dispositional mindfulness' protective role against other problematic behaviours (e.g., pathological gambling), this study assessed its influence on the relationship between problematic gaming and subjective well-being. A sample of 514 frequent gamers $\left(37.9 \%\right.$ female; $\underline{M}_{\text {age }}=$ 22.56 years, $S D=4.3$ ) completed an online survey. Structural equation modelling revealed that dispositional mindfulness partially negatively mediated the relationship between problematic gaming and both life satisfaction and negative affectivity while fully positively mediating that between problematic gaming and positive affectivity, suggesting dispositional mindfulness may be clinically useful in problematic gaming prevention and interventions.
\end{abstract}

Keywords Dispositional mindfulness . Problematic gaming . Subjective well-being . Positive affectivity . Negative affectivity . Life satisfaction

Playing video games is a leisure activity that can benefit overall well-being and mental health in many ways, including reduced emotional disturbance, better emotion regulation, stress reduction and greater life satisfaction (Granic et al. 2014; Jones et al. 2014). It has mass appeal because of the wide variety of genres (e.g., role playing, action adventure, puzzle games), levels of complexity (from simple puzzle games to open-world story-driven role- playing games) and type of play (e.g., single player, multiplayer online, multiplayer offline) that video games offer. 
Given this range of diversity, it is not surprising that over half of the population in USA (Entertainment Software Association [ESA] 2015) and Canada (Entertainment Software Association of Canada [ESAC] 2015) report playing video games. Moreover, similar prevalence rates have been found in other countries, including Korea (Seok and DaCosta 2012), the Netherlands (Lemmens et al. 2015), and Taiwan (Ko et al. 2005). Further, contrary to popular belief, the majority of video game players are adults and the gender distribution of video game players is approximately equal between males and females (e.g., Elliott et al. 2012; ESA 2015; ESAC 2015; Kirby et al. 2014; Kowert et al. 2012; Williams 2003; Williams et al. 2008). However, playing video games can become problematic for some individuals, which can negatively impact their subjective well-being (e.g., Mentzoni et al. 2011). Moreover, research has shown that mindfulness, which can be defined as purposeful and non-judgmental present moment awareness, can be protective against problematic engagement in behaviours that may be conceptually similar to gaming, such as pathological gambling or problematic Internet use (Calvete et al. 2017; de Lisle et al. 2012; Gámez-Guadix and Calvete 2016; Mazzoni et al. 2017). Thus, the present study seeks to further explore this potential role of mindfulness within the relationship between problematic gaming and subjective well-being.

Problematic gaming can be defined as a pattern of gaming that has negative impacts on individuals' social, academic/occupational or psychological functioning (e.g., Griffiths et al. 2016; King et al. 2013). A meta-analysis by Ferguson et al. (2011) of 33 studies concluded that problematic gaming affects 3 to $9 \%$ of individuals in the general population overall. Moreover, although the gender distribution of individuals who play video games is nearly equal, gender differences in terms of problematic gaming are still unclear, with most studies finding that males report higher levels of problematic gaming symptoms (e.g., Gentile et al. 2011; Lemmens et al. 
This is a post-peer-review, pre-copyedit version of an article published in 'International Journal of Mental Health and Addiction'. The final authenticated version is available online at: https://doi.org/10.1007/s11469-018-9978-5.

2015; Mentzoni et al. 2011; Müller et al. 2015; Rehbein et al. 2010; Rehbein et al. 2015).

However, when controlling for game genre, other studies have reported no gender differences in terms of problematic gaming (Elliott et al. 2012; Przybylski et al. 2017).

One of the factors contributing to discrepancies of prevalence rates is the lack of a universally accepted operational definition of what problematic gaming entails (Ferguson et al. 2011). Some of the terms used to refer to this construct reflect this, with terms such as problematic gaming, pathological gaming, Internet gaming disorder and gaming addiction being used. Subsequently, one of the main issues with the current state of research is that, due to the lack of a uniform definition of the construct, there are several different screening measures that each assesses problematic gaming in a slightly different way, thus making comparison across studies difficult.

In an attempt to standardize a conceptual definition, the fifth edition of the Diagnostic and Statistical Manual for Mental Disorders (DSM-5; American Psychiatric Association 2013) proposed a set of nine diagnostic criteria for Internet gaming disorder which are currently under review as a condition for further study. These include being pre-occupied with gaming, losing interest in other activities and continuation of gaming despite being aware of significant and persistent negative consequences in other domains of life (i.e., neglecting work or academic responsibilities). However, these diagnostic criteria were based on those used to assess gambling disorder or substance use addiction and have been criticised for not accurately reflecting problematic gaming as a separate construct (e.g., Billieux et al. 2015; Griffiths et al. 2016; Kardefelt-Winther 2015).

Despite disagreement in the conceptualisation of problematic gaming, one of the key features which seems to be uniformly recognised is the negative effect it has on overall well- 
being and its interference in other domains of an individual's life due to a strong preoccupation for gaming (e.g., Griffiths et al. 2016; Petry et al. 2014). For instance, gaming may be considered problematic when it results in severe and persistent psychosocial (e.g., interference with academic or job performance) or health (e.g., loss of sleep) consequences. Increasingly, research has demonstrated that problematic gaming should not be confounded with greater time spent gaming or a high level of enthusiasm towards gaming (i.e., high gaming engagement); rather, it is best understood as a pattern of gaming that directly interferes with the individual's life and contributes to negative outcomes (e.g., Charlton and Danforth 2010; Majamäki and Hellman 2016). Thus, it is important to distinguish between high gaming engagement and problematic gaming.

Given the negative impact problematic gaming can have on other domains of an individual's life, the association between problematic gaming and subjective well-being is of specific interest to the present study. Well-being is a broad construct with a wide scope of interpretation; however, it can be examined through specific theoretical models. For instance, subjective well- being, which is individuals'subjective evaluation of their happiness and quality of life, has been conceptualised as the experience of high life satisfaction, frequent positive affect and infrequent negative affect (Diener 2000). Reports of subjective well-being tend to fluctuate around a set point for each individual, which in turn can be affected by long-term life circumstances as adaptation occurs (Diener 2000). Additionally, research has shown that the tendency to experience infrequent positive affect or frequent negative affect has a different pattern of convergent validity; for instance, a tendency towards experiencing low frequency of positive affect is associated with symptoms of depression, whereas a tendency towards experiencing high frequency of negative affect is associated with both anxiety and depression. 
This is a post-peer-review, pre-copyedit version of an article published in 'International Journal of Mental Health and Addiction'. The final authenticated version is available online at: https://doi.org/10.1007/s11469-018-9978-5.

Therefore, it can be considered a broader indicator of psychiatric disorders (Watson et al. 1988). Importantly, video gaming in general is not inherently problematic and has in fact been associated with a variety of positive outcomes, including improving emotion regulation, forming new friend- ships, obtaining emotional support online, enhancing cognitive functions and increasing positive affect and life satisfaction (see reviews by Granic et al. 2014; Jones et al. 2014; Uttal et al. 2013). For instance, a 2-year longitudinal study by Kowert et al. (2015) of over 4500 adolescent and adult video game players in Germany found that regular gaming (i.e., nonproblematic gaming) was not a risk factor for low self-esteem, low sociability or increased loneliness.

Further, it is not high gaming frequency that contributes to negative outcomes but the extent to which individuals endorse problematic gaming symptoms that can negatively contribute to overall well-being. In fact, when video gaming becomes problematic, one of the key characteristics is the negative impact on an individual's life (Griffiths and Meredith 2009). Several studies have found that problematic gamers report significantly lower well-being across different aspects, including the experience of higher depression, anxiety, and loneliness as well as lower life satisfaction, family functioning and self-esteem (Kirby et al. 2014; Hagström and Kaldo 2014; Mentzoni et al. 2011; Scott and Porter-Armstrong 2013; Van Rooij et al. 2011; Wartberg et al. 2015). For example, Kirby et al. (2014) conducted an online survey of adult gamers and demonstrated that, although greater time spent gaming predicted lower psychological well-being, this relationship was fully mediated by problematic gaming such that greater problematic gaming predicted lower well-being (i.e., anxiety, insomnia, depression, social functioning and somatic problems). Similarly, a study with Norwegian young adults revealed that problematic gamers reported significantly lower levels of life satisfaction and greater levels 
of anxiety and depression than either non-problematic gamers or non-gamers (Mentzoni et al. 2011).

It has also been proposed that lower psychosocial well-being may in fact be a cause of problematic gaming. For instance, a study by Lemmens et al. (2011) found that some aspects of lower psychosocial well-being such as lower social competence and self-esteem predicted increased problematic gaming over a 6-month period, while increased loneliness was found to both predict and be predicted by problematic gaming. Similarly, a cross-sectional study by Hull et al. (2013) revealed that experiencing low general happiness was associated with problematic gaming. However, this may be specific to certain aspects of overall well-being. Results from a longitudinal study by Scharkow et al. (2014) revealed that, across groups of adolescents, young adults and adults above 40 years of age, problematic gaming scores predicted lower life satisfaction over a 2-year period only for adults over 40. Additionally, they used cross-lagged structural equation modelling to investigate a reverse model whereby life satisfaction would predict engagement in problematic gaming and failed to find significant associations over time across any of the age groups.

Given the mixed findings in previous research, the relationship between problematic gaming and overall well-being seems to be complex and potentially recursive, with both problematic gaming and well-being negatively influencing one another. In a related area, Muusses et al. (2014) investigated such a recursive relationship between problematic Internet use and subjective well-being over a one-year period. Findings indicated that although greater problematic Internet use predicted lower happiness and greater depression, stress and loneliness one year later, only happiness in turn negatively predicted problematic Internet use (Muusses et al. 2014). 
This is a post-peer-review, pre-copyedit version of an article published in 'International Journal of Mental Health and Addiction'. The final authenticated version is available online at: https://doi.org/10.1007/s11469-018-9978-5.

However, one of the recently proposed models of problematic gaming suggests that it is a compensatory behaviour used to cope with problems, worries or emotions (Kardefelt-Winther 2014). This is in line with DSM-5 diagnostic criteria which state that one of the symptoms of Internet gaming disorder is using video games as a means of escaping from negative moods, such as helplessness, guilt, anxiety or depression (American Psychiatric Association 2013). Therefore, it is not surprising that a study investigating gaming motivations revealed that, using a stepwise regression, problematic gaming was most strongly predicted by negative escapism or the desire to avoid everyday problems, worries and situations, compared to time spent playing, game mechanics or socialisation (Hagström and Kaldo 2014). Furthermore, it is possible that the detrimental impact of problematic gaming on other domains of life, such as work, school, or relationships as well as on overall well-being may potentially further contribute to increase negative escapism or avoidance tendencies resulting in more problematic gaming. It would therefore be important to identify factors, such as mindfulness, that have been shown to enhance non-avoidant coping, subjective well-being and adaptive functioning and may therefore help disrupt this cycle (e.g., Brown et al. 2007; Brown et al. 2015; Soysa and Wilcomb 2015; Weinstein et al. 2009).

With roots in ancient Buddhist practices, mindfulness is a complex construct that has been secularised and increasingly used over the past 40 years in Western psychological and medical interventions and research (e.g., Kabat-Zinn 2003; van Gordon et al. 2015; Williams et al. 2007). Although there are different ways of conceptualising mindfulness (for in-depth reviews of existing conceptualisations, see for example Bodhi 2011; Dunne 2015; Gethin 2015; Hart et al. 2013; Khoury et al. 2017), one of the most common Western practices defines mindfulness as a quality of consciousness that is purposefully aware of the present moment experience, with a 
non-judgmental acceptance of thoughts, feelings and sensations (e.g., Kabat-Zinn 1994, 2013).

Mindfulness can be conceptualised as either a unitary construct focusing on the quality of attention and awareness in the present moment (e.g., Brown and Ryan 2003) or as a multidimensional construct consisting of several interacting facets (e.g., Baer et al. 2006). Although a multi-dimensional model of mindfulness can be important to obtain detailed information about complex relationships, employing a uni-dimensional model, such as the one assessed using the Mindful Attention and Awareness Scale (Brown and Ryan 2003), can be beneficial as an initial approach to establish a relationship between mindfulness and variables of interest, particularly in light of the well-established use of this measure (e.g., see systematic review by Park et al. 2013). Furthermore, within these conceptualisations, mindfulness can be assessed as either a state, which reflects moment-by-moment experience of mindfulness, or a dispositional trait, which reflects individuals' tendency to be mindful in general (e.g., Brown and Ryan 2003). Given its dynamic nature and impact on positive treatment outcomes, the present study focuses on dispositional mindfulness specifically. Importantly, higher dispositional mindfulness has been found to predict higher levels of state (i.e., day-to-day) mindfulness (Brown and Ryan 2003), and mindfulness-based interventions have been shown to significantly increase dispositional mindfulness (Khoury et al. 2013; Shapiro et al. 2011). Additionally, individuals with higher dispositional mindfulness have been shown to have better outcomes in terms of increased life satisfaction, positive affectivity, empathy, and dispositional mindfulness as well as decreased negative affectivity up to one year following mindfulness interventions (Shapiro et al. 2011). Although mindfulness-based therapy has been proposed as a possible treatment for problematic gaming (Dong and Potenza 2014; Li et al. 2017), there is a lack of research investigating the relationship between dispositional mindfulness and problematic gaming. However, within a 
This is a post-peer-review, pre-copyedit version of an article published in 'International Journal of Mental Health and Addiction'. The final authenticated version is available online at: https://doi.org/10.1007/s11469-018-9978-5.

related area, research has demonstrated an inverse association between dispositional mindfulness and reports of problematic gambling or Internet use (Calvete et al. 2017; de Lisle et al. 2012; Gámez-Guadix and Calvete 2016; Mazzoni et al. 2017); thus, it is possible that dispositional mindfulness may present a similar inverse association with problematic gaming.

Finally, greater dispositional mindfulness has been associated with greater subjective well- being, reduced anxiety and depression, as well as a more flexible and adaptive ability to self- regulate emotional, behavioural and physiological responses to stressful situations (Brown et al. 2007; Cash and Whittingham 2010; Friese and Hofmann 2016; Kadziolka et al. 2016; Keng et al. 2011; Schutte and Malouff 2011; Soysa and Wilcomb 2015). For instance, research has shown that mindfulness may reduce automatized responding, enhance behavioural self- control, promote autonomous self-regulation and facilitate goal attainment (Brown et al. 2007; Keng et al. 2011). Given that problematic gaming may be a compensatory coping behaviour (KardefeltWinther 2014), dispositional mindfulness may be particularly helpful in enhancing selfregulation and promoting greater flexibility and ability to switch attention from an immersive activity that could potentially have negative consequences. Therefore, it is possible that the association between problematic gaming and elements of subjective well-being is at least partially explained or mediated by individuals' reports of dispositional mindfulness.

As a first step in determining the potential influence of dispositional mindfulness on the relationship between problematic gaming and subjective well-being, the overall objectives of the current study were to (a) assess the relationships between problematic gaming, dispositional mindfulness and dimensions of subjective well-being (life satisfaction and frequency of positive and negative affect) and (b) evaluate the influence of dispositional mindfulness as a possible mediator between problematic gaming and subjective well-being. Specifically, it was 
hypothesised that higher reports of problematic gaming would predict lower dispositional mindfulness (H1a) and overall subjective well-being (low life satisfaction and positive affectivity, high negative affectivity; H1b). Meanwhile, reports of higher dispositional mindfulness would predict greater overall subjective well-being (H1c). Finally, it was also hypothesised that, when controlling for gender and hours spent gaming per week, dispositional mindfulness would mediate the relationship between symptoms of problematic gaming and the three aspects of subjective well-being: life satisfaction (H2a), positive affectivity (H2b) and negative affectivity $(\mathrm{H} 2 \mathrm{c})$.

\section{Method}

\section{Participants and Procedure}

A total of 1032 participants at least partially responded to the online survey. The data were initially screened to remove all participants who had failed to either complete at least half of the survey $(n=228)$, properly answer one or both of the attention items $(n=93)$ or provide their gender $(n=6)$ or information regarding whether they game most days of the week (i.e., frequent video game use; $n=7$ ). To assess frequent video game use, participants were specifically asked BDo you play video games (i.e., any game played on an electronic device) most days of the week? Two participants failed to report their age and had to be removed due to ethics requirements that all participants be 18 and over. Prior to running analyses, all data were cleaned separately within gender groups. Results from a Missing Value Analysis revealed that all variables had less than $5 \%$ of missing values; therefore, the data could be assumed to be missing completely at random. As expected, the same pattern of results was obtained for analyses conducted using list-wise deletion compared to using the expectation-maximisation method (Tabachnick and Fidell 2007). Therefore, in order to maintain an unbiased dataset, the 28 
This is a post-peer-review, pre-copyedit version of an article published in 'International Journal of Mental Health and Addiction'. The final authenticated version is available online at: https://doi.org/10.1007/s11469-018-9978-5.

participants with missing values were removed using list-wise deletion. Subsequently, participants who did not report frequent video game use $(n=135)$ or were above 3 standard deviations removed from the mean age $(n=15)$ were excluded. Finally, four individuals were removed following data cleaning for being multivariate outliers. Therefore, the final sample size used for analyses consisted of 514 frequent gamers (37.9\% female; $M_{\mathrm{age}}=22.56$ years, $S D=4.3$ ) who reported playing video games most days of the week and thus were classified as frequent gamers.

The average reported number of hours spent gaming per week was $14.98(S D=12.06$; Median $=12 \mathrm{~h})$. Most participants reported either residing in Canada $(45.5 \%)$ or the United States (35\%), with a minority reporting European (8.4\%) or Asian (6.6\%) countries of residence. Furthermore, $75.5 \%$ reported currently being enrolled in university with more than half working over $31 \mathrm{~h}$ per week.

\section{Measures}

Problematic Video Game Use To assess levels of problematic video game use in young adults, a revised version of the Addiction-Engagement Questionnaire (Charlton 2002; Charlton and Danforth 2007, 2010) was used. This revised questionnaire consists of 10 items on a 7-point Likert scale (Completely agree to Completely disagree), including items such as BI tend to want to spend increasing amounts of time playing video games or BI continue to play games even though I am aware of negative consequences, such as not getting enough sleep, being late to school or work, spending too much money, having arguments with others, or neglecting important duties. Nine of the items correspond to the recently proposed DSM-5 diagnostic criteria for Internet gaming disorder (see Petry et al. 2014), with a tenth item assessing the experience of euphoria during gaming. Higher scores were indicative of greater reports of 
problematic gaming symptoms. The internal consistency of this 10 -item scale was found to be adequate for the present study (Cronbach's $\alpha=0.77$ ).

Dispositional Mindfulness The Mindful Awareness and Attention Scales (MAAS; Brown and Ryan 2003), a 15-item self-report questionnaire, was used to assess dispositional mindfulness. This questionnaire was designed to measure a lack of mindful awareness in daily life given that mindlessness (as opposed to mindful states) was deemed to be more accessible to most people (Brown and Ryan 2003). Items are rated on a 6-point Likert scale ranging from almost always (1) to almost never (6), with higher total scores reflecting greater reports of dispositional mindfulness. Examples of items include BI find it difficult to stay focused on what's happening in the present. or BI forget a person's name almost as soon as I've been told it for the first time. In the current study, the MAAS demonstrated excellent reliability with a Cronbach's alpha of 0.88 , which is comparable to original reliability levels ranging from 0.82 to 0.87 (Brown and Ryan 2003).

Positive and Negative Affectivity The International Positive and Negative Affect Schedule-Short Form (I-PANAS-SF; Thompson 2007) was used in order to assess the general dispositional tendency to experience positive and negative affect (i.e., affectivity). This scale consists of ten words (e.g., "Determined", “Inspired", "Upset”, “Ashamed”) with the instruction to rate how frequently each emotion is generally experienced (i.e., how participants feel most of the time) using a 5-point scale ranging from very slightly or not at all to extremely. The ten words correspond to two 5-item subscales assessing positive and negative emotions, with higher scores reflecting higher frequency of experiencing each emotion. In the present study, the IPANAS-SF had a Cronbach's alpha of 0.79 for negative affectivity and 0.73 for positive affectivity, therefore demonstrating acceptable reliability comparable to that found in the original 
This is a post-peer-review, pre-copyedit version of an article published in 'International Journal of Mental Health and Addiction'. The final authenticated version is available online at: https://doi.org/10.1007/s11469-018-9978-5.

validation sample (Cronbach's alpha of 0.74 for negative affectivity and 0.80 for positive;

Thompson 2007). Additionally, the scale has been found to have moderately good test-retest reliability after a period of 8 weeks, $r=0.84, p<0.01$ (Thompson 2007).

Life Satisfaction The Satisfaction With Life Scale (SWLS; Diener et al. 1985) was used to measure individuals' reports of life satisfaction in general. This self-report scale consists of 5 items such as "In most ways, my life is close to my ideal" or "So far, I have gotten the important things I want in life". Each item is rated on a 7-point scale ranging from not agree at all to very strongly agree, with higher scores reflecting greater life satisfaction. The SWLS was found to have excellent reliability in the present study (Cronbach's $\alpha=0.91$ ) similar to that found in the original validation sample (Cronbach's $\alpha=0.87$; Diener et al. $\underline{1985}$ ).

\section{Procedure}

Adult participants were recruited from a variety of sources including social media websites (e.g., Reddit, Facebook) and gaming websites, flyers distributed across a Canadian university campus and email invitations to an existing pool of undergraduate students interested in participating in research studies. The survey was completed online, and participants were offered entry into a raffle for one of ten Amazon gift cards (50\$) if they fully completed it. Only individuals who indicated they were 18 or over and frequently played video games (i.e., answered Byes^ to a dichotomous item asking whether he/she played video games most days of the week) were subsequently included in the analyses. This study was approved by the university’s Institutional Ethics Review Board.

\section{Data Analysis}

All data were analysed using either SPSS 24 or MPlus 7.4. Pearson correlation coefficients were used to examine the associations between problematic gaming, dispositional 
mindfulness and subjective well-being. Structural equation modelling (SEM) was then used to assess the relationships among problematic gaming, dispositional mindfulness and elements of subjective well-being as well as to test the hypothesised mediation models using MPlus 7.4. Given the chi-square test's sensitivity to large sample sizes, model fit was evaluated based on Comparative Fit Index (CFI) and Tucker-Lewis fit index (TLI) values and Root Mean Square Error of Approximation (RMSEA). Moderately good model fit was determined by CFI/TLI values over 0.90 and RMSEA below 0.08 , while very good model fit was determined by CFI/TLI values over 0.95 and an RMSEA value below 0.06 (Hu and Bentler 1999; Vandenberg and Lance 2000). As per recommendations by Hayes (2013) and Tabachnick and Fidell (2007), mediation effects were determined by comparing the direct effect of X (i.e., problematic gaming) on Y (i.e., the elements of subjective well-being) and the indirect effect of $\mathrm{X}$ on $\mathrm{Y}$ through the influence of the mediator (i.e., dispositional mindfulness). Significant indirect effects indicated that the influence of the mediator was statistically significant. Full versus partial mediation was then established by examining whether the direct effect of $\mathrm{X}$ on $\mathrm{Y}$ when the mediator was included in the structural model remained significant or not. A nonsignificant direct effect indicated full mediation (i.e., the influence of X on Y only occurred through the impact of X on the mediator and the impact of the mediator on Y) while a significant direct effect indicated partial mediation (i.e., even when taking into account the influence of the mediator, X still significantly had a unique direct influence on Y).

\section{Results}

Descriptive statistics for dispositional mindfulness, problematic gaming, subjective wellbeing, time spent gaming, and gender are reported in Table $\underline{1}$. Additionally, Table $\underline{2}$ presents the Pearson's correlation coefficients for the study variables. As expected, problematic gaming 
This is a post-peer-review, pre-copyedit version of an article published in 'International Journal of Mental Health and Addiction'. The final authenticated version is available online at: https://doi.org/10.1007/s11469-018-9978-5.

was inversely correlated to dispositional mindfulness and subjective well-being (which can be defined as high life satisfaction and positive affectivity, low negative affectivity). However, dispositional mindfulness and elements of subjective well-being were positively associated with one another.

To evaluate the mediational role of dispositional mindfulness in the relationship between problematic gaming and subjective well-being when controlling for gender and hours spent gaming per week, a full latent model was tested using Maximum Likelihood Estimation with robust standard errors (MLR) in MPlus 7.4. The sample size of 514 was deemed appropriate based on recommendations by Bentler and Chou (1987) given the large number of indicators per latent factor. First, the present data were fit to measurement models by running three separate CFAs. Results indicated a moderately good fit for problematic gaming, $\chi^{2}(35)=99.56, p<$ $0.001, \mathrm{CFI}=0.93, \mathrm{TLI}=0.90, \mathrm{RMSEA}=0.06[0.05,0.07]$, with standardized estimates ranging from 0.25 to 0.68 . It is important to note that although the range of standardized estimates was from 0.25 to 0.68 , only two items loaded below 0.30 ; thus, we chose to retain these items in our model to allow for comparisons with further studies and to facilitate generalization across datasets. However, the CFA model for dispositional mindful- ness was initially a marginal fit, $\chi^{2}$ $(90)=320.15, p<0.001, \mathrm{CFI}=0.89, \mathrm{TLI}=0.88, \mathrm{RMSEA}=0.07[0.06,0.08]$; therefore, two pairs of items were allowed to correlate with one another based on a review of the modifications indices. This revised model was significantly better, as shown by the decrease in AIC value, and resulted in a good fit, $\chi^{2}(88)=241.23, p<0.001, \mathrm{CFI}=0.93, \mathrm{TLI}=0.92, \mathrm{RMSEA}=0.06[0.05$, 0.07], with standardised estimates ranging from 0.35 to 0.83 . Meanwhile, a good fit was observed for subjective well-being, $\chi^{2}(87)=210.96, p<0.001, \mathrm{CFI}=0.96$, TLI $=0.95$, RMSEA $=0.05[0.04,0.06]$, with standardised estimates ranging from 0.70 to 0.92 for life satisfaction, 
0.49 to 0.69 for positive affectivity and 0.36 to 0.74 for negative affectivity.

Following the assessment of the measurement models, a full structural equation model was run. This hypothesised model resulted in a marginal fit, $\chi^{2}(798)=1550.65$, CFI $=0.89$, TLI $=0.88$, RMSEA $=0.04[0.04,0.05]$. However, in order to obtain a better fit, a revised model was run. First, the theoretically relevant modifications suggested based on the modification indices in model 1 were incorporated. Secondly, in order to have a more parsimonious model, all nonsignificant paths in model 1 (i.e., problematic gaming to positive affectivity, gender to life satisfaction and mindfulness, as well as weekly hours of gaming to negative affectivity) were removed in the revised model (Byrne 2012). The revised model was significantly improved, as determined by the decrease in AIC values, and these modifications resulted in a moderately good fit for model $2, \chi^{2}(799)=1463.16, \mathrm{CFI}=0.90, \mathrm{TLI}=0.90, \mathrm{RMSEA}=0.04[0.037$, 0.043]. Figure 1 is a graphical representation of model 2 in which the standardised coefficients of each path are presented.

As hypothesised, while controlling for gender and hours spent gaming per week, problematic gaming significantly predicted lower dispositional mindfulness (H1a). However, contrary to $\mathrm{H} 1 \mathrm{~b}$, although problematic gaming significantly predicted lower life satisfaction while also predicting greater frequency of negative affect, there was no direct effect of problematic gaming on frequency of positive affect. Meanwhile, dispositional mindfulness significantly positively predicted life satisfaction and positive affectivity while negatively predicting negative affectivity (H1c). Finally, examination of the indirect effects revealed that, when co- varying for gender and hours spent gaming per week, dispositional mindfulness was a significant mediator of the relationship between problematic gaming and each aspect of subjective well-being. Specifically, results revealed a significant negative indirect effect of 
This is a post-peer-review, pre-copyedit version of an article published in 'International Journal of Mental Health and Addiction'. The final authenticated version is available online at: https://doi.org/10.1007/s11469-018-9978-5.

dispositional mindfulness on the relationship between problematic gaming and life satisfaction (H2a), $\beta=-0.05, S E=0.02, p=0.014$, as well as between problematic gaming and positive affectivity (H2b), $\beta=-0.09, S E=0.03, p<0.001$. Additionally, a significant positive indirect effect of dispositional mindfulness on the relationship between problematic gaming and negative affectivity was found $(\mathrm{H} 2 \mathrm{c}), \beta=0.14, \mathrm{SE}=0.03, p<0.001$.

Although dispositional mindfulness significantly mediated the relationship between problematic gaming and both life satisfaction and negative affect, there was still a significant direct effect of problematic gaming on both life satisfaction and negative affectivity; therefore, the influence of dispositional mindfulness only partially explained these relationships. In other words, even when taking into account the influence of dispositional mindfulness, problematic gaming still significantly predicted both life satisfaction and negative affectivity. However, given the lack of a direct effect of problematic gaming on positive affectivity, dispositional mindfulness fully mediated this relationship; therefore, the influence of problematic gaming on positive affectivity was fully explained by individuals' reports of dispositional mindfulness.

\section{Discussion}

The primary objective of the current study was to investigate the influence of dispositional mindfulness on the relationship between problematic gaming and subjective wellbeing (de- fined in this context as high life satisfaction and positive affectivity, as well as low negative affectivity). Specifically, it was proposed that problematic gaming would be inversely related with both dispositional mindfulness (H1a) and overall subjective well-being (H1b) and that dispositional mindfulness would be positively associated with overall subjective well-being (H1c). Additionally, it was hypothesised that, when controlling for gender and hours spent gaming per week, dispositional mindfulness would mediate the relationship between problem- 
atic gaming and life satisfaction (H2a), positive affectivity (H2b) and negative affectivity (H2c). Consistent with previous research (e.g., Mentzoni et al. 2011), results supported the hypoth- esis that higher levels of problematic gaming would significantly predict lower positive affectivity and life satisfaction, as well as greater negative affectivity. Moreover, similar to findings from research in related areas showing negative relationships between mindfulness and both pathological gambling and problematic Internet use (Calvete et al. 2017; de Lisle et al. 2012; Gámez-Guadix and Calvete 2016; Mazzoni et al. 2017), the level of problematic gaming symptoms reported by frequent gamers negatively predicted dispositional mindfulness.

Furthermore, in a study investigating the association between mindfulness and video gaming in general, Gackenbach and Bown (2011) demonstrated that highly engaged video game players (who report high frequency of play, duration of gaming periods and number of games played over their lifetime as well as having started to play games at a young age) reported greater state mindfulness than those with low engagement. An aspect of both being mindful and choosing to play video games is the ability to consciously choose to focus attention, and in fact mindfulness and playing video games in general have both been shown to enhance attentional control (e.g., Bavelier et al. 2012; Becerra et al. 2017; see review by Green and Bavelier 2012; Vega et al. 2014). Therefore, it is not unexpected that highly engaged players would report higher levels of state mindfulness; however, more research is needed to elucidate this relationship.

These findings provide further support for the need to differentiate the mechanisms underlying high gaming engagement versus problematic gaming given their inverse associa- tion with mindfulness (Charlton and Danforth 2007, 2010; Loton et al. 2016). This is especially important considering that high engagement with gaming (as opposed to problem- atic gaming) 
This is a post-peer-review, pre-copyedit version of an article published in 'International Journal of Mental Health and Addiction'. The final authenticated version is available online at: https://doi.org/10.1007/s11469-018-9978-5.

does not inherently negatively impact other domains of individuals' lives and that gamers who are passionate about gaming, and yet not problematically engaged with gaming, are flexible in their gaming engagement based on their life situation (e.g., Billieux et al. 2013; Majamäki and Hellman 2016).

As hypothesised, results also revealed that low dispositional mindfulness helped explain the overall negative association between problematic gaming and overall subjective well-being. Interestingly, while a partial mediation was found for both life satisfaction and negative affectivity, dispositional mindfulness fully explained the relationship between problematic gaming and positive affectivity. In other words, problematic gaming had a detrimental influence on life satisfaction and the frequency of experience of negative affect partially through individuals' low dispositional mindfulness. However, given that this is a partial mediation, even when dispositional mindfulness is being taken into account, problematic gaming is still negatively associated with life satisfaction and positively associated with the frequency of experience of negative affect. Meanwhile, having low dispositional mindfulness fully explains the detrimental association between problematic gaming and positive affectivity; therefore, once dispositional mindfulness is taken into account, problematic gaming no longer has a negative relationship with the frequency of experience of positive affect.

A potential explanation for this could be that some of the adverse life consequences that occur for individuals who engage in problematic gaming (e.g., missing school or work) are present in these individuals' lives regardless of their dispositional mindfulness and may have a negative impact on their life satisfaction and the frequency with which they report negative affect. Meanwhile, reporting a higher number of problematic gaming symptoms may not influence the frequency of experiencing positive affect because individuals with problematic 
gaming engagement may experience positive affect through their gaming which may mitigate the impact of adverse life consequences on positive affectivity. For instance, a study by Reinecke (2009) demonstrated that gamers who reported experiencing stress, work-related strain or daily hassles were more likely to play video games for recovery reasons, especially if they also had an emotion-focused coping style, in an attempt to self-regulate.

Recent research on mindfulness has explored ways in which mindfulness training can be used to enhance positive psychological functioning and act as a protective factor against mental health problems (e.g., Bajaj and Pande 2016; Brown et al. 2015; Grossman et al. 2004). One of the ways that mindfulness may be beneficial in terms of problematic gaming is through its ability to enable individuals to cope without engaging in avoidance tendencies. For instance, research by Weinstein et al. (2009) has shown that individuals who are more mindful not only report perceiving situations as being less stressful but are also less likely to use avoidance strategies and/or more likely to use approach strategies depending on the context. This is particularly interesting given recent findings by Hagström and Kaldo (2014) that higher reports of negative escapism (i.e., a motivation to escape from or avoid real-life problems or worries) emerged as the strongest predictor of greater problematic gaming and lower life satisfaction when taking into account gaming motivations for achievement or socialisation. If one of the principal gaming motivations of individuals who report problematic gaming symptoms is to avoid or escape from adverse life events, mindfulness training may enable them to become aware of these avoidance tendencies and learn to approach and respond to adverse situations with a more adaptive coping strategy. Thus, the present findings build on this growing body of knowledge and support the recently suggested notion that mindfulness may be clinically useful in assisting individuals engaging in problematic gaming (Dong and Potenza 2014; Li et al. 2017). 
This is a post-peer-review, pre-copyedit version of an article published in 'International Journal of Mental Health and Addiction'. The final authenticated version is available online at: https://doi.org/10.1007/s11469-018-9978-5.

Unfortunately, due to the cross-sectional nature of this study, causation cannot be inferred. Longitudinal designs are required to clarify the role of dispositional mindfulness in problem- atic gaming and to determine, for instance, whether individuals with low dispositional mindfulness are more likely to develop problematic gaming habits or whether individuals who game problematically experience lower dispositional mindfulness over time.

Interestingly, contrary to common stereotypes (e.g., Kowert et al. 2012), a longitudinal study examining other aspects of psychosocial well-being (loneliness, self-esteem, social competence and life satisfaction) revealed that loneliness, low self-esteem and low selfcompetence were a cause rather than being a consequence of problematic gaming (Lemmens et al. 2011). Given the lack of research on dispositional mindfulness and problematic gaming, the current study used a cross-sectional design to investigate the potential role of dispositional mindfulness in the relationship between problematic gaming and subjective well- being before investing resources in a longitudinal design. However, given the indications that dispositional mindfulness is negatively associated with problematic gaming and that some aspects of lower well-being could be a precursor to problematic gaming, future studies should employ a prospective design to assess factors associated with problematic gaming across its development over time. Further studies should also consider exclusion criteria (e.g., for comorbidity with depression or anxiety as well as medication usage) to obtain more detailed information regarding the heterogeneity of participants.

Furthermore, given that data were collected online from individuals who chose to participate, a self-selection gender bias may have occurred during recruitment. Due to common gender stereotypes around video gaming and the fact that females are less likely to self-identify as Bgamers^ compared to males (e.g., Shaw 2011; Williams 2003), it may be that females were 
less willing to participate in a study focusing on video gaming. Future studies should take this into account in the design stage by possibly using a quota system that is embedded in survey software.

Finally, although widely employed and well-validated (Park et al. 2013), the measure used to assess dispositional mindfulness in this study has a unidimensional structure tapping specifically in the lack of attention and awareness associated with mindlessness (Brown and Ryan 2003). Given the preliminary nature of this study, it was deemed best to assess dispositional mindfulness using this measure because of its well-established psychometric properties and its generalisability across groups with different experiences with mindfulness (e.g., Brown and Ryan 2003; Park et al. 2013). However, other researchers have proposed a multi-factorial structure in which dispositional mindfulness consists of five inter-acting facets (Baer et al. 2006); therefore, it could also be useful for future studies to investigate which aspects of dispositional mindfulness contribute most to the relationship between problematic gaming and subjective well-being.

In conclusion, findings from this study suggest that, in a sample of frequent gamers, the negative relationship between problematic gaming and elements of subjective well-being can be explained through individuals' low dispositional mindfulness. Specifically, low reports of dispositional mindfulness partially explained the detrimental influence of problematic gaming on life satisfaction and negative affectivity, while fully explaining the influence on positive affectivity. Given it has been found that dispositional mindfulness can be a dynamic factor modifiable through mindfulness practice (e.g., Khoury et al. 2013), findings from the present study could help clarify the potential utility of using mindfulness training to help individuals who report high levels of problematic gaming cope with associated dysfunctions in other domains of 
This is a post-peer-review, pre-copyedit version of an article published in 'International Journal of Mental Health and Addiction'. The final authenticated version is available online at: https://doi.org/10.1007/s11469-018-9978-5.

\section{their life.}




\section{References}

American Psychiatric Association. (2013). Diagnostic and statistical manual of mental disorders (5th ed.). Washington, DC: American Psychiatric Association.

Baer, R. A., Smith, G. T., Hopkins, J., Krietemeyer, J., \& Toney, L. (2006). Using self-report assessment methods to explore facets of mindfulness. Assessment, 13(1), 27-45. https://doi.org/10.1177/1073191105283504.

Bajaj, B., \& Pande, N. (2016). Mediating role of resilience in the impact of mindfulness on life satisfaction and affect as indices of subjective well-being. Personality and Individual Differences, 93, 63-67. https://doi. org/10.1016/j.paid.2015.09.005.

Bavelier, D., Achtman, R. L., Mani, M., Föcker, J. (2012). Neural bases of selective attention in action video game players. Vision Research, 61, 132-143. https://doi.org/10.1016/j.visres.2011.08.007.

Becerra, R., Dandrade, C., \& Harms, C. (2017) Can specific attentional skills be modified with mindfulness training for novice practitioners? Current Psychology, 36(3), 657-664. https://doi.org/10.1007/s12144-016-9454-y.

Bentler, P. M., \& Chou, C.-P. (1987). Practical issues in structural modeling. Sociological Methods \& Research, 16(1), 78-117.

Billieux, J., Van Der Linden, M., Achab, S., Khazaal, Y., Paraskevopoulos, L., Zullino, D., \& Thorens, G. (2013). Why do you play World of Warcraft? An in-depth exploration of self-reported motivations to play online and in-game behaviours in the virtual world of Azeroth. Computers in Human Behavior, 29, 103-109. https://doi.org/10.1016/j.chb.2012.07.021.

Billieux, J., Thorens, G., Khazaal, Y., Zullino, D., Achab, S., \& Van Der Linden, M. (2015). 
This is a post-peer-review, pre-copyedit version of an article published in 'International Journal of Mental Health and Addiction'. The final authenticated version is available online at: https://doi.org/10.1007/s11469-018-9978-5.

Problematic involvement in online games: a cluster analytic approach. Computers in Human Behavior, 43, 242-250. https://doi.org/10.1016/j.chb.2014.10.055.

Bodhi, B. (2011) What does mindfulness really mean? A canonical perspective. Contemporary Buddhism, 12(1), 19-39.

Brown, K. W., \& Ryan, R. M. (2003). The benefits of being present: mindfulness and its role in psychological well-being. Journal of Personality and Social Psychology, 84(4), 822-848. https://doi.org/10.1037/0022-3514.84.4.822.

Brown, K. W., Ryan, R. M., \& Creswell, J. D. (2007). Mindfulness: theoretical foundations and evidence for its salutary effects. Psychological Inquiry, 18(4), 211-237. https://doi.org/10.1080/10478400701598298.

Brown, K. W., Creswell, J. D., \& Ryan, R. M. (2015). Handbook of mindfulness: theory, research and practice. New York: The Guilford Press.

Byrne, B. M. (2012). Structural equation modeling with Mplus: basic concepts, applications, and programming. New York: Routledge.

Calvete, E., Gámez-Guadix, M., \& Cortazar, N. (2017). Mindfulness facets and problematic Internet use: a six- month longitudinal study. Addictive Behaviors, 72, 57-63. https://doi.org/10.1016/j.addbeh.2017.03.018.

Cash, M., \& Whittingham, K. (2010). What facets of mindfulness contribute to psychological well-being and depressive, anxious, and stress-related symptomatology? Mindfulness, 1(3), 177-182. https://doi. org/10.1007/s12671-010-0023-4.

Charlton, J. P. (2002). A factor-analytic investigation of computer Baddiction^ and engagement. British Journal of Psychology, 93(3), 329-344. https://doi.org/10.1348/000712602760146242. 
Charlton, J. P., \& Danforth, I. D. W. (2007). Distinguishing addiction and high engagement in the context of online game playing. Computers in Human Behavior, 23(3), 1531-1548. https://doi.org/10.1016/j. chb.2005.07.002.

Charlton, J. P., \& Danforth, I. D. W. (2010). Validating the distinction between computer addiction and engagement: online game playing and personality. Behaviour \& Information Technology, 29(6), 601-613. https://doi.org/10.1080/01449290903401978.

de Lisle, S. M., Dowling, N. A., \& Allen, J. S. (2012). Mindfulness and problem gambling: a review of the literature. Journal of Gambling Studies, 28(4), 719-739. https://doi.org/10.1007/s10899-011-9284-7.

Diener, E. (2000). The science of happiness and a proposal for a national index. The American Psychologist, 55(1), 34-43. https://doi.org/10.1037/0003-066X.55.1.34.

Diener, E., Emmons, R. A., Larsen, R. J., \& Griffin, S. (1985). The satisfaction with life scale. Journal of Personality Assessment, 49, 71-75.

Dong, G., \& Potenza, M. N. (2014). A cognitive-behavioral model of Internet gaming disorder: theoretical underpinnings and clinical implications. Journal of Psychiatric Research, 58, 7-11. https://doi.org/10.1016/j. jpsychires.2014.07.005.

Dunne, J. D. (2015). Buddhist styles of mindfulness: A heuristic approach. In B. D. Ostafin, M. D. Robinson, \& B. P. Meier (Eds.), Handbook of mindfulness and self-regulation. New York: Springer.

Elliott, L., Golub, A., Ream, G., \& Dunlap, E. (2012). Video game genre as a predictor of problem use. Cyberpsychology, Behavior and Social Networking, 15(3), 155-161. https://doi.org/10.1089/cyber.2011.0387.

Entertainment Software Association (2015). 2015 Essential facts about the computer and video 
This is a post-peer-review, pre-copyedit version of an article published in 'International Journal of Mental Health and Addiction'. The final authenticated version is available online at: https://doi.org/10.1007/s11469-018-9978-5.

game industry.

Retrieved from http://www.theesa.com/facts/pdfs/ESA_EF_2008.pdf.

Entertainment Software Association of Canada (ESAC). (2015). 2015 Essential facts about the

Canadian video game industry. Retrieved from http://theesa.ca/wpcontent/uploads/2015/11/ESAC_2015_Booklet_Version02_14_Digital.pdf

Ferguson, C. J., Coulson, M., \& Barnett, J. (2011). A meta-analysis of pathological gaming prevalence and comorbidity with mental health, academic and social problems. Journal of Psychiatric Research, 45(12), 1573-1578.

https://doi.org/10.1016/j.jpsychires.2011.09.005.

Friese, M., \& Hofmann, W. (2016). State mindfulness, self-regulation, and emotional experience in everyday life. Motivation Science, 2(1), 1-14. https://doi.org/10.1037/mot0000027.

Gackenbach, J., \& Bown, J. (2011). Mindfulness and video game play: a preliminary inquiry. Mindfulness, 2(2), 114-122. https://doi.org/10.1007/s12671-011-0049-2.

Gámez-Guadix, M., \& Calvete, E. (2016). Assessing the relationship between mindful awareness and problematic Internet use among adolescents. Mindfulness, 7, 1281-1288. https://doi.org/10.1007/s12671-016-0566-0.

Gentile, D. A., Choo, H., Liau, A., Sim, T., Li, D., Fung, D., \& Khoo, A. (2011). Pathological video game use among youths: a two-year longitudinal study. Pediatrics, 127(2), e319e329. https://doi.org/10.1542/peds.2010-1353.

Gethin, R. (2011). On some definitions of mindfulness. Contemporary Buddhism, 12(1), 263-27. https://doi. org/10.1080/14639947.2011.564843.

Granic, I., Lobel, A., \& Engels, R. C. M. E. (2014). The benefits of playing video games. American Psychologist, 69(1), 66-78. https://doi.org/10.1037/a0034857. 
Green, C.S., \& Bavelier, D. (2012). Learning, attentional control, and action video games. Current Biology, 22(6), R197-R206. https://doi.org/10.1016/j.cub.2012.02.012.

Griffiths, M. D., \& Meredith, A. (2009). Videogame addiction and its treatment. Journal of Contemporary Psychotherapy, 39(4), 247-253. https://doi.org/10.1007/s10879-009-9118$\underline{4}$.

Griffiths, M. D., van Rooij, A. J., Kardefelt-Winther, D., Starcevic, V., Király, O., Pallesen, S., Müller, K., Dreier, M., Carras, M., Prause, N., King, D. L., Aboujaoude, E., Kuss, D. J., Pontes, H. M., Lopez Fernandez, O., Nagygyorgy, K., Achab, S., Billieux, J., Quandt, T., Carbonell, X., Ferguson, C. J., Hoff, R. A., Derevensky, J., Haagsma, M. C., Delfabbro, P., Coulson, M., Hussain, Z., Demetrovics, Z., \& Demetrovics, Z. (2016). Working towards an international consensus on criteria for assessing Internet gaming disorder: a critical commentary on Petry et al. (2014). Addiction, 111(1), 167-175. https://doi.org/10.1111/add.13057.

Grossman, P., Niemann, L., Schmidt, S., \& Walach, H. (2004). Mindfulness-based stress reduction and health benefits: a meta-analysis. Journal of Psychosomatic Research, 57(1), 35-43. https://doi.org/10.1016/S0022- 3999(03)00573-7.

Hagström, D., \& Kaldo, V. (2014). Escapism among players of MMORPGs—conceptual clarification, its relation to mental health factors, and development of a new measure. Cyberpsychology, Behavior and Social Networking, 17(1), 19-25. https://doi.org/10.1089/cyber.2012.0222.

Hart, R., Ivtzan, I., \& Hart, D. (2013). Mind the gap in mindfulness research: A comparative account of the leading schools of thought. Review of General Psychology, 17(4), 453466. https://doi.org/10.1037 
This is a post-peer-review, pre-copyedit version of an article published in 'International Journal of Mental Health and Addiction'. The final authenticated version is available online at: https://doi.org/10.1007/s11469-018-9978-5.

$\underline{\text { la0035212639947.2011.564843. }}$.

Hayes, A. F. (2013). Introduction to mediation, moderation, and conditional process analysis: A regression-based approach. New York: The Guilford Press.

Hu, L. T., \& Bentler, P. M. (1999). Cutoff criteria for fit indexes in covariance structure analysis: conventional criteria versus new alternatives. Structural Equation Modeling: A Multidisciplinary Journal, 6(1), 1-55.

Hull, D. C., Williams, G. A., \& Griffiths, M. D. (2013). Video game characteristics, happiness and flow as predictors of addiction among video game players: a pilot study. Journal of Behavioral Addictions, 2(3), 145-152. https://doi.org/10.1556/JBA.2.2013.005.

Jones, C. M., Scholes, L., Johnson, D., Katsikitis, M., \& Carras, M. C. (2014). Gaming well: links between videogames and flourishing mental health. Frontiers in Psychology, 5(MAR), 1-8. https://doi.org/10.3389/fpsyg.2014.00260.

Kabat-Zinn, J. (1994). Wherever you go, there you are. New York: Hyperion.

Kabat-Zinn, J. (2003). Mindfulness-based interventions in context: Past, present, and future. American Psychological Association. https://doi.org/10.1093/clipsy/bpg016.

Kabat-Zinn, J. (2013). Full catastrophe living (revised edition): using the wisdom of your body and mind to face stress, pain, and illness. New York: Bantam Books.

Kadziolka, M. J., Di Pierdomenico, E. A., \& Miller, C. J. (2016). Trait-like mindfulness promotes healthy self- regulation of stress. Mindfulness, 7(1), 236-245. https://doi.org/10.1007/s12671-015-0437-0.

Kardefelt-Winther, D. (2014). A conceptual and methodological critique of Internet addiction research: towards a model of compensatory Internet use. Computers in Human Behaviour, 31, 351-354. https://doi.org/10.1016 
j.chb.2013.10.059.

Kardefelt-Winther, D. (2015). A critical account of DSM-5 criteria for Internet Gaming Disorder. Addiction Research \& Theory, 23(2), 93-98. https://doi.org/10.3109/16066359.2014.935350.

Keng, S.-L., Smoski, M. J., \& Robins, C. J. (2011). Effects of mindfulness on psychological health: a review of empirical studies. Clinical Psychology Review, 31, 1041-1056. https://doi.org/10.1016/j.cpr.2011.04.006.

Khoury, B., Knäuper, B., Pagnini, F., Trent, N., Chiesa, A., \& Carrière, K. (2017). Embodied Mindfulness.

Mindfulness. https://doi.org/10.1007/s12671-017-0700-7

Khoury, B., Lecomte, T., Fortin, G., Masse, M., Therien, P., Bouchard, V., Chapleau, M. A., Paquin, K., \& Hofmann, S. G. (2013). Mindfulness-based therapy: a comprehensive meta-analysis. Clinical Psychology Review, 33(6), 763-771. https://doi.org/10.1016/j.cpr.2013.05.005.

King, D. L., Haagsma, M. C., Delfabbro, P. H., Gradisar, M., \& Griffiths, M. D. (2013). Toward a consensus definition of pathological video-gaming: a systematic review of psychometric assessment tools. Clinical Psychology Review, 33(3), 331-342. https://doi.org/10.1016/j.cpr.2013.01.002.

Kirby, A., Jones, C., \& Copello, A. (2014). The impact of massively multiplayer online role playing games (MMORPGs) on psychological wellbeing and the role of play motivations and problematic use. International Journal of Mental Health Addiction, 12, 36-51. https://doi.org/10.1007/s11469-013-9467-9.

Ko, C.-H., Yen, J.-Y., Chen, C.-C., Chen, S.-H., \& Yen, C.-F. (2005). Gender differences and 
This is a post-peer-review, pre-copyedit version of an article published in 'International Journal of Mental Health and Addiction'. The final authenticated version is available online at: https://doi.org/10.1007/s11469-018-9978-5.

related factors affecting online gaming addiction among Taiwanese adolescents. The Journal of Nervous and Mental Disease, 193(4), 273-277.

Kowert, R., Griffiths, M. D., \& Oldmeadow, J. (2012). Geek or chic? Emerging stereotypes of online gamers. Bulletin of Science, Technology \& Society, 32(6), 471-479. https://doi.org/10.1177/0270467612469078.

Kowert, R., Vogelgesang, J., Festl, R., \& Quandt, T. (2015). Psychosocial causes and consequences of online video game play. Computers in Human Behavior, 45, 51-58. https://doi.org/10.1016/j.chb.2014.11.074.

Lemmens, J. S., Valkenburg, P. M., \& Peter, J. (2011). Psychosocial causes and consequences of pathological gaming. Computers in Human Behavior, 27(1), 144-152. https://doi.org/10.1016/j.chb.2010.07.015.

Lemmens, J. S., Valkenburg, P. M., \& Gentile, D. A. (2015). The Internet Gaming Disorder Scale. Psychological Assessment, 27(2), 567-582. https://doi.org/10.1037/pas0000062. Li, W., Garland, E. L., O’Brien, J. E., Tronnier, C., McGovern, P., Anthony, B., \& Howard, M. O. (2017). Mindfulness-oriented recovery enhancement for video game addiction in emerging adults: preliminary findings from case reports. International Journal of Mental Health Addiction. https://doi.org/10.1007/s11469-017-9765-8.

Loton, D., Borkoles, E., Lubman, D., \& Polman, R. (2016). Video game addiction, engagement and symptoms of stress, depression and anxiety: the mediating role of coping. International Journal of Mental Health Addiction, 14, 565-578. https://doi.org/10.1007/s11469-015-9578-6.

Majamäki, M., \& Hellman, M. (2016). BWhen sense of time disappears^^—or does it? Online video gamers' time management and time apprehension. Time \& Society, 25(2), 355- 
373. $\underline{\text { https://doi.org/10.1177/0961463 }} \underline{\text { X15577265. }}$.

Mazzoni, E., Cannata, D., \& Baiocco, L. (2017). Focused, not lost: the mediating role of temporal dissociation and focused immersion on problematic Internet use. Behaviour \& Information Technology, 36(1), 11-20. https://doi.org/10.1080/0144929X.2016.1159249.

Mentzoni, R. A., Brunborg, G. S., Molde, H., Myrseth, H., Skouverøe, K. J. M., Hetland, J., \& Pallesen, S. (2011). Problematic video game use: estimated prevalence and associations with mental and physical health. Cyberpsychology, Behavior and Social Networking, 14(10), 591-596. https://doi.org/10.1089/cyber.2010.0260.

Müller, K. W., Janikian, M., Dreier, M., Wölfling, K., Beutel, M. E., Tzavara, C., Richardson, C., \& Tsitsika, A. (2015). Regular gaming behavior and internet gaming disorder in European adolescents: results from a cross- national representative survey of prevalence, predictors, and psychopathological correlates. European Child \& Adolescent Psychiatry, 24(5), 565-574. https://doi.org/10.1007/s00787-014-0611-2.

Muusses, L. D., Finkenauer, C., Kerkhof, P., \& Billedo, C. J. (2014). A longitudinal study of the association between compulsive Internet use and wellbeing. Computers in Human Behavior, 36, 21-28. https://doi. org/10.1016/j.chb.2014.03.035.

Park, T., Reilly-Spong, M., \& Gross, C. R. (2013). Mindfulness: a systematic review of instruments to measure an emergent patient-reported outcome (PRO). Quality of Life Research: an International Journal of Quality of Life Aspects of Treatment, Care and Rehabilitation, 22(10), 2639-2659. https://doi.org/10.1007/s11136- 013-0395-8.

Petry, N. M., Rehbein, F., Gentile, D. A., Lemmens, J. S., Rumpf, H. J., Moßle, T., et al. (2014). An international consensus for assessing Internet gaming disorder using the new DSM-5 approach. Addiction, 109(9), 1399-1406. https://doi.org/10.1111/add.12457. 
This is a post-peer-review, pre-copyedit version of an article published in 'International Journal of Mental Health and Addiction'. The final authenticated version is available online at: https://doi.org/10.1007/s11469-018-9978-5.

Przybylski, A. K., Weinstein, N., \& Muyarama, K. (2017). Internet gaming disorder: investigating the clinical relevance of a new phenomenon. American Journal of Psychiatry, 174(3), 230-235. https://doi.org/10.1176/appi.ajp.2016.16020224.

Rehbein, F., Kleimann, M., \& Mößle, T. (2010). Prevalence and risk factors of video game dependency in adolescence: results of a German nationwide survey. Cyberpsychology, Behavior, and Social Networking, 13(3), 269-277. https://doi.org/10.1089/cyber.2009.0227.

Rehbein, F., Kliem, S., Baier, D., Mößle, T., \& Petry, N. M. (2015). Prevalence of Internet Gaming Disorder in German adolescents: diagnostic contribution of the nine DSM-5 criteria in a statewide representative sample. Addiction, 110(5), 842-851. https://doi.org/10.1111/add.12849.

Reinecke, L. (2009). Games and recovery: the use of video and computer games to recuperate from stress and strain. Journal of Media Psychology, 21(3), 126-142.

Scharkow, M., Festl, R., \& Quandt, T. (2014). Longitudinal patterns of problematic computer game use among adolescents and adults—a 2-year panel study. Addiction, 109(11), 1910-1917. https://doi.org/10.1111/add.12662.

Schutte, N. S., \& Malouff, J. M. (2011). Emotional intelligence mediates the relationship between mindfulness and subjective well-being. Personality and Individual Differences, 50(7), 1116-1119. https://doi.org/10.1016/j.paid.2011.01.037.

Scott, J., \& Porter-Armstrong, A. P. (2013). Impact of multiplayer online role-playing games upon the psycho- social well-being of adolescents and young adults: reviewing the evidence. Psychiatry Journal, 2013, 8 pages. https://doi.org/10.1155/2013/464685. Seok, S., \& DaCosta, B. (2012). The world's most intense online gaming culture: 
addiction and high-engagement prevalence rates among South Korean adolescents and young adults. Computers in Human Behavior, 28, 2143-2151. https://doi.org/10.1016/j.chb.2012.06.019.

Shapiro, S. L., Brown, K. W., Thoresen, C., \& Plante, T. G. (2011). The moderation of mindfulness-based stress reduction effects by trait mindfulness: results from a randomized controlled trial. Journal of Clinical Psychology, 67(3), 267-277. https://doi.org/10.1002/jclp.20761.

Shaw, A. (2012) Do you identify as a gamer? Gender, race, sexuality, and gamer identity. New Media \& Society, 14(1), 28-44.

Soysa, C. K., \& Wilcomb, C. J. (2015). Mindfulness, self-compassion, self-efficacy, and gender as predictors of depression, anxiety, stress, and well-being. Mindfulness, 6(2), 217-226. https://doi.org/10.1007/s12671-013- 0247-1.

Tabachnick, B. G., \& Fidell, L. S. (2007). Using multivariate statistics. Boston: Pearson Education, Inc.. Thompson, E. R. (2007). Development and validation of an internationally reliable short-form of the Positive and Negative Affect Schedule (PANAS). Journal of Cross-Cultural Psychology, 38(2), 227242. https://doi. org/10.1177/0022022106297301.

Uttal, D. H., Meadow, N. G., Tipton, E., Hand, L. L., Alden, A. R., Warren, C., \& Newcombe, N. S. (2013). The malleability of spatial skills: a meta-analysis of training studies. Psychological Bulletin, 139(2), 352-402. https://doi.org/10.1037/a0028446.

van Gordon, W., Shonin, E., Griffiths, M. D., \& Singh, N. N. (2015). There is only one mindfulness: Why science and Buddhism need to work together. Mindfulness, 6, 49-56. https://doi.org/10.1007/s12671-014- 0379-y. 
This is a post-peer-review, pre-copyedit version of an article published in 'International Journal of Mental Health and Addiction'. The final authenticated version is available online at: https://doi.org/10.1007/s11469-018-9978-5.

Van Rooij, A. J., Schoenmakers, T. M., Vermulst, A. A., Van Den Eijnden, R. J. J. M., \& Van De Mheen, D. (2011). Online video game addiction: identification of addicted adolescent gamers. Addiction, 106(1), 205-212. https://doi.org/10.1111/j.1360-0443.2010.03104.x.

Vandenberg, R. J., \& Lance, C. E. (2000). A review and synthesis of the measurement invariance literature: suggestions, practices, and recommendations for organizational research. Organizational Research Methods, 3(1), 4-70.

Vega, B. R., Melero-Llorente, J., Perez, C. B., Cebolla, S., Mira, J., Valverde, C., \& FernándezLiria, A. (2014). Impact of mindfulness training on attentional control and anger regulation processes for psychotherapists in training. Psychotherapy Research, 24(2), 202-213. https://doi.org/10.1080/10503307.2013.838651.

Wartberg, L., Kriston, L., Kammerl, R., Petersen, K. U., \& Thomasius, R. (2015). Prevalence of pathological Internet use in a representative German sample of adolescents: results of a latent profile analysis. Psychopathology, 48(1), 25-30. https://doi.org/10.1159/000365095.

Watson, D., Clark, L. A., \& Carey, G. (1988). Positive and negative affectivity and their relation to anxiety and depressive disorders. Journal of Abnormal Psychology, 97(3), 346-353. https://doi.org/10.1037/0021-843 X.97.3.346.

Weinstein, N., Brown, K. W., \& Ryan, R. M. (2009). A multi-method examination of the effects of mindfulness on stress attribution, coping, and emotional well-being. Journal of Research in Personality, 43, 374-385. https://doi.org/10.1016/j.jrp.2008.12.008.

Williams, D. (2003). The video game lightning rod. Information, Communication \& Society, 6(4), 523-550. https://doi.org/10.1080/1369118032000163240.

Williams, M., Teasdale, J., Segal, Z., \& Kabat-Zinn, J. (2007). The mindful way through 
depression: Freeing yourself from chronic unhappiness. New York: The Guilford Press.

Williams, D., Yee, N., \& Caplan, S. E. (2008). Who plays, how much, and why? Debunking the stereotypical gamer profile. Journal of Computer-Mediated Communication, 13(4), 9931018. https://doi.org/10.1111/j.1083-6101.2008.00428.x. 
This is a post-peer-review, pre-copyedit version of an article published in 'International Journal of Mental Health and Addiction'. The final authenticated version is available online at: https://doi.org/10.1007/s11469-018-9978-5.

\section{Tables and Figures}

Table 1 Means and standard deviations for problematic gaming symptoms, dispositional mindfulness and subjective well-being for males and females

\begin{tabular}{|c|c|c|c|c|}
\hline & \multicolumn{2}{|c|}{$\begin{array}{l}\text { Males }(n= \\
319)\end{array}$} & \multicolumn{2}{|c|}{$\begin{array}{l}\text { Females }(n= \\
195)\end{array}$} \\
\hline & $M$ & $S D$ & $M$ & $S D$ \\
\hline Problematic gaming & 22.12 & 6.14 & 19.27 & 5.7 \\
\hline Dispositional mindtulness & 3.92 & 0.83 & 3.93 & 0.82 \\
\hline Lite satistaction & 19.94 & 1.35 & 20.10 & 1.80 \\
\hline Positive attect & 16.38 & 3.48 & 15.38 & $3 . / 8$ \\
\hline Negative atfect & 10.77 & 3.99 & 10.97 & 3.90 \\
\hline
\end{tabular}

Table 2 Correlation matrix indicating the associations between problematic gaming, dispositional mindfulness, subjective well-being, time spent gaming and gender

$\begin{array}{lllllll}1 & 2 & 3 & 4 & 5 & 6 & 7\end{array}$

\begin{tabular}{|c|c|c|c|c|c|c|}
\hline 1. Problematic gaming & - & & & & & \\
\hline $\begin{array}{l}\text { 2. Dispositional } \\
\text { mindfulness }\end{array}$ & $-0.28^{* *}$ & - & & & & \\
\hline 3. Lite satistaction & $-0.28^{* *}$ & $0.21 * *$ & - & & & \\
\hline 4. Positive attect & $-0.16^{* *}$ & $0.2 /^{* *}$ & $0.4 /^{* *}$ & - & & \\
\hline 5. Negatıve attect & $0.36^{* *}$ & $-0.46^{* *}$ & $-0.53^{* \pi}$ & $-U .22^{* *}$ & - & \\
\hline o. Iime spent gaming & $0.2 y^{* *}$ & U.ur & $-U .10^{\pi \pi}$ & $-U . U /$ & -0.01 & - \\
\hline 7. Gender & $-0.23 * *$ & 0.01 & 0.01 & $-0.13 *$ & 0.03 & $-0.23 * *$ \\
\hline
\end{tabular}

Gender was coded as male $=1$, female $=2$

${ }^{*} p<0.01$

** $p<0.001$ 


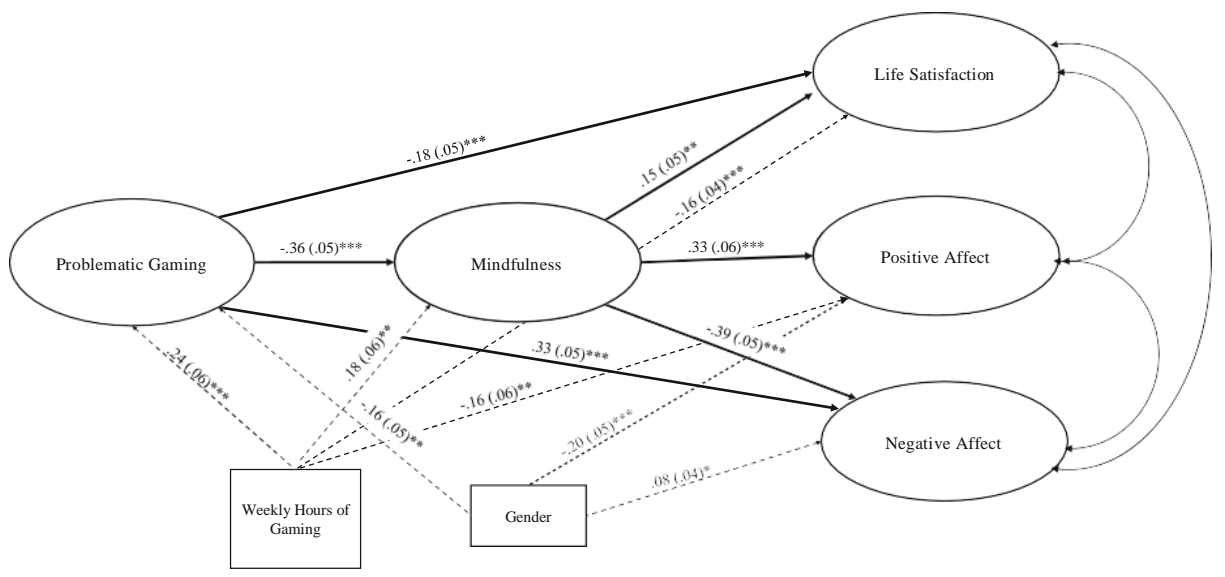

Fig. 1 Final estimated model of the mediation of dispositional mindfulness on the relation between problematic gaming and subjective well-being. Standardised regression coefficients and standard errors are presented for each path $(* p<0.05, * * p<0.01, * * * p<0.001)$ 